\title{
SOSIALISASI PENERAPAN ISAK 35 DALAM PENYAJIAN LAPORAN KEUANGAN KEPADA PENGURUS MASJID AL- AULIA, PEKALONGAN
}

\author{
Jaenal Abidin ${ }^{1}$, Ayumi Rahma ${ }^{2}$ \\ Jalan Cabe Raya, Pondok Cabe, Pamulang, Tangerang, Banten \\ Email Korespondensi: jaenalabidin328@gmail.com
}

\begin{abstract}
ABSTRAK
Masjid Al-Aulia dikategorikan sebagai organisasi nirlaba sehingga penyusunan laporan keuangan akan berbeda dengan organisasi berorientasi laba. Dengan disahkannya PPSAK 13, maka PSAK 45 sebagai pedoman penyusunan laporan keuangan bagi organisasi nirlaba dihapuskan, dan digantikan dengan ISAK 35 sebagai dasar penyusunan laporan keuangan. Berdasarkan perubahan tersebut, maka perlu dilakukan sosialisasi penerapan ISAK 35 dalam penyajian laporan keuangan Masjid Al-Aulia bagi pengurus Masjid. Dengan sosialisasi ini, diharapkan pengurus Masjid dapat menyajikan laporan keuangan yang transparan dan tepat bagi donatur dan dapat meningkatkan kepercayaan para donatur. Sosialisasi ini dilaksanakan pada 13 - 15 November 2020 di Antasari Indah, Jalan Pangeran Antasari No.37, Cipete Selatan, Cilandak, Jakarta Selatan. PKM ini bertujuan unuk untuk memperkenalkan penerapan ISAK 35 dalam penyusunan laporan keuangan bagi organisasi nirlaba. Para peserta yang merupakan pengurus Masjid Al-Aulia cukup antusias mengikuti pelatihan ini untuk dapat menambah pemahaman akan perbedaan PSAK 45 dengan ISAK 35. Untuk kegiatan pengabdian berikutnya diharapkan dapat memberikan strategi lanjutan dalam pengembangan bisnis secara berkesinambungan.

Berdasarkan permasalahan di atas, maka perlu dilakukan sosialisasi dalam penyajian laporan keuangan yang sesuai dengan ISAK 35 kepada pengurus Masjid Al-Aulia, Pekalongan sehingga diperoleh laporan keuangan yang akuntabel dan transparan.
\end{abstract}

Kata Kunci : SAK, Entitas Nonlaba, ISAK 35, Penyajian Laporan Keuangan

\section{ABSTRACT}

Al-Aulia Mosque is categorized as a non-profit organization so that the preparation of financial reports will be different from profit-oriented organizations. With the ratification of PPSAK 13, PSAK 45 as a guideline for preparing financial reports for non-profit organizations was abolished and replaced with ISAK 35 as the basis for preparing financial statements. Based on these changes, it is necessary to socialize the application of ISAK 35 in presenting the financial statements of the Al-Aulia Mosque for mosque administrators. With this socialization, it is hoped that the mosque management can present transparent and accurate financial reports for donors and can increase the trust of donors. This socialization was held on November 13-152020 at Antasari Indah, Jalan Pangeran Antasari No.37, Cipete Selatan, Cilandak, South Jakarta. This PKM aims to introduce the application of ISAK 35 in the preparation of financial reports for nonprofit organizations. The participants who are the administrators of the Al-Aulia Mosque are enthusiastic about participating in this training to be able to increase their understanding of the differences between PSAK 45 and ISAK 35. For the next service activities, it is hoped that they can provide further strategies in sustainable business development. Based on the above problems, it is necessary to conduct socialization in the presentation of financial statements in accordance with ISAK 35 to the management of the Al-Aulia Mosque, Pekalongan in order to obtain accountable and transparent financial reports. 
Keywords : SAK, non profit entity, ISAK 35, Financial reports

PENDAHULUAN

Rencana renovasi untuk memperbaiki dan meningkatkan kapasitas Masjid Al-Aulia membutuhkan pengumpulan dana dari masyarakat dan donatur untuk memenuhi kebutuhan pendanaan yang cukup besar. Dengan mempertimbangan kondisi area Masjid yang kerap digenangi banjir rob, terbatasnya kapasitas Masjid serta sebagai antisipasi rencana perluasan jalan, pengurus Masjid sepakat untuk mengadakan perluasan dan renovasi Masjid Al-Aulia sebagai peningkatan pelayanan bagi jamaah yang akan beribadah.

Sebagai wujud pertanggung jawaban atas dana sumbangan yang dari masyarakat dan donatur, pengurus Masjid telah menyusun laporan keuangan secara periodik dan disampaikan secara terbuka. Penyusunan laporan keuangan yang akuntabel dipandang perlu untuk dapat menambah calon donatur untuk memenuhi kebutuhan pendanaan agar proses renovasi dapat berjalan dengan lancar dan sesuai dengan tenggat waktu yang telah direncanakan.

Dengan disahkannya PPSAK 13, dan penggantian PSAK 45 dengan ISAK 35 sebagai pedoman penyusunan laporan keuangan bagi organisasi nirlaba membutuhkan pemahaman atas penerapan standar baru dalam pelaporan keuangan agar penyajian laporan keuangan secara tepat dapat dipenuhi. Pelaporan keuangan secara tepat dan akuntabel dibutuhkan untuk menjaga kepercayaan donatur sekaligus mempersiapkan kemungkinan untuk pengajuan pendanaan dari debitur baru yang mempersyaratkan adanya laporan keuangan.

Akan tetapi, hal ini juga menjadi tantangan tersendiri. Bagi masyarakat awam, penyusunan laporan keuangan untuk sebuah Masjid masih menjadi hal yang "tabu". Laporan keuangan dianggap identik dengan sektor bisnis. Oleh karena itu, masyarakat masih menganggap penyusunan laporan keuangan sebagai komersialisasi rumah ibadah. Namun, penyusunan laporan keuangan untuk rumah ibadah seperti Masjid bukan berarti rumah ibadah disamakan dengan bisnis. Entitas berorientasi non laba seperti masjid juga membutuhkan laporan keuangan sebagai bentuk pertanggungjawaban pengurus atas dana masyarakat yang dikelolanya.

Penyusun laporan keuangan bagi organisasi nirlaba berbeda dengan laporan keuangan organisasi berorientasi laba dalam hal cara memperoleh sumber daya yang tidak mengharapkan pembayaran kembali atau manfaat ekonomis tidak dibandingkan dengan sumber daya yang diberikan. Dengan sosialisasi yang diadakan tim dosen Universitas Pamulang, diharapkan dapat memberikan pemahaman kepada pengurus Masjid dalam penyusunan laporan keuangan Masjid sebagai organisasi nirlaba.

Perbedaan utama entitas nirlaba dengan entitas bisnis terletak pada tujuannya. Tujuan utama entitas bisnis adalah memperoleh laba sedangkan entitas nirlaba merupakan entitas yang tidak berorientasi pada laba. Perbedaan lainnya terletak pada cara entitas memperoleh sumber daya. Entitas nirlaba memperoleh sumber daya dari sumbangan anggota dan penyumbang yang tidak mengharapkan imbalan.

Entitas nirlaba tetap menghasilkan barang dan/atau jasa namun tanpa bertujuan untuk memupuk laba. Jika entitas nirlaba menghasilkan laba, hasilnya tersebut tidak dibagikan kepada para pendiri atau pemilik entitas nirlaba. Selain itu, Tidak ada kepemilikan seperti lazimnya pada entitas bisnis, dalam arti bahwa kepemilikan dalam entitas nirlaba tidak dapat dijual, dialihkan, atau ditebus kembali, atau kepemilikan tersebut tidak mencerminkan proporsi pembagian sumber daya entitas nirlaba pada saat likuidasi atau pembubaran entitas nirlaba. 
Meskipun tidak bertujuan mencari laba, namun entitas nirlaba tetap memiliki kewajiban untuk mempertanggungjawabkan pemanfaatan sumber daya yang dikelolanya kepada penyandang dana dan society. Salah satu media pertanggungjawabannya adalah Laporan Keuangan.

Karakteristik entitas berorientasi nonlaba berbeda dengan entitas bisnis berorientasi laba. Perbedaan utama yang mendasar antara entitas berorientasi nonlaba dengan entitas bisnis berorientasi laba terletak pada cara entitas berorientasi nonlaba memperoleh sumber daya yang dibutuhkan untuk melakukan berbagai aktivitas operasinya. Entitas berorientasi nonlaba memperoleh sumber daya dari pemberi sumber daya yang tidak mengharapkan pembayaran kembali atau manfaat ekonomik yang sebanding dengan jumlah sumber daya yang diberikan.

Pengguna laporan keuangan entitas berorientasi nonlaba umumnya memiliki kepentingan untuk menilai :

1. Cara manajemen melaksanakan tanggung jawab atas penggunaan sumber daya yang dipercayakan kepada mereka

2. Informasi mengenai posisi keuangan, kinerja keuangan dan arus kas entitas yang bermanfaat dalam pembuatan keputusan ekonomik. Kemampuan entitas berorientasi nonlaba dalam menggunakan sumber daya tersebut dikomunikasikan melalui laporan keuangan.

Dengan diadopsinya IAS 1 Presentation of Financial Statements menjadi PSAK 1: Penyajian Laporan Keuangan, maka Dewan Standar Akuntansi Keuangan memandang perlu untuk menerbitkan Interpretasi Standar Akuntansi Keuangan yang memberikan pedoman penyajian laporan keuangan untuk entitas berorientasi nonlaba. ISAK 35: Penyajian Laporan Keuangan Entitas Berorientasi Nonlaba mengatur tentang penyajian laporan keuangan entitas berorientasi nonlaba. ISAK 35: Penyajian Laporan Keuangan Entitas Berorientasi Nonlaba yang diterbitkan oleh DSAK IAI merupakan interpretasi dari PSAK 1: Penyajian Laporan Keuangan paragraf 05 yang memberikan contoh bagaimana entitas berorientasi nonlaba membuat penyesuaian baik: (i) penyesuaian deskripsi yang digunakan untuk pos-pos tertentu dalam laporan keuangan; dan (ii) penyesuaian deskripsi yang digunakan untuk laporan keuangan itu sendiri. ISAK 35: Penyajian Laporan Keuangan Entitas Berorientasi Nonlaba dilengkapi dengan contoh ilustratif dan dasar kesimpulan yang bukan merupakan bagian dari ISAK 35: Penyajian Laporan Keuangan Entitas Berorientasi Nonlaba.

PSAK 1: Penyajian Laporan Keuangan paragraf 05 menyatakan bahwa "Pernyataan ini menggunakan terminologi yang cocok bagi entitas yang berorientasi laba, termasuk entitas bisnis sektor publik. Jika entitas dengan aktivitas nonlaba di sektor swasta atau sektor publik menerapkan Pernyataan ini, maka entitas tersebut mungkin perlu menyesuaikan deskripsi yang digunakan untuk beberapa pos yang terdapat dalam laporan keuangan dan laporan keuangan itu sendiri." Dengan demikian, ruang lingkup PSAK 1 secara substansi telah mencakup ruang lingkup penyajian laporan keuangan entitas dengan aktivitas nonlaba. PSAK 1: Penyajian Laporan Keuangan tidak menyediakan pedoman bagaimana entitas dengan aktivitas nonlaba menyajikan laporan keuangannya. Entitas dengan aktivitas nonlaba dalam Interpretasi ini selanjutnya merujuk kepada entitas berorientasi nonlaba.

Pada tanggal yang sama, yaitu 19 April 2019, Dewan Standar Akuntansi Keuangan Ikatan Akuntan Indonesia (DSAK IAI) juga mengesahkan PPSAK 13 Pencabutan PSAK 45: Pelaporan Keuangan Entitas Nirlaba. Pernyataan ini bertujuan untuk mencabut 
pemberlakuan PSAK 45. Sebelum ISAK 35: Penyajian Laporan Keuangan Entitas Berorientasi Nonlaba disahkan, laporan keuangan entitas nirlaba menggunakan PSAK 45 sebagai dasar dalam penyusunan laporan keuangan. Namun, dalam praktiknya PSAK 45: Pelaporan Keuangan Entitas Nirlaba malah membingungkan karena adanya pengaturan penyajian laporan keuangan yang berbeda dalam kelompok standar (tier) yang sama.

\section{METODE KEGIATAN}

Pelaksanaan kegiatan dengan metode memberikan pemaparan yang disertai dengan diskusi interaktif secara langsung antara kelompok dosen pelaksana PKM dan peserta. Pemberian materi dilakukan diawal pertemuan selama pelaksanaan. Adapun sistematika pelaksanaan kegiatan pengabdian adalah sebagai berikut:

a. Metode Ceramah

Metode ceramah dipilih untuk memberikan wawasan mengenai perlunya penerapan Prinsip Akuntansi Berlaku Umum dalam penysuan laporan keuangan entitas nonlaba seperti Masjid Al-Aulia. Selain itu juga akan diberikan materi mengenai bagaimana penerapan Standar Akuntansi Keuangan khususnya ISAK 35: Penyajian Laporan Keuangan Entitas Berorientasi Nonlaba dalam penyajian laporan keuangan terutama untuk organisasi non laba seperti masjid Al-Aulia.

b. Metode Tutorial

Metode tutorial ini diberikan kepada para peserta pelatihan agar peserta mendapatkan kesempatan untuk mempraktekkan materi yang diperoleh. Tutorial diperlukan agar pengurus Masjid Al-Aulia Pekalongan lebih memahami bagaimana ISAK 35: Penyajian Laporan Keuangan Entitas Berorientasi Nonlaba diterapkan dalam penyajian laporan keuangan. Kami juga akan membimbing mitra dalam membuat laporan keuangan agar penyajiannya sesuai dengan ISAK 35: Penyajian Laporan Keuangan Entitas Berorientasi Nonlaba

c. Metode Diskusi

Metode diskusi sangat penting bagi para peserta PKM. Metode ini memungkinkan mitra untuk menggali pengetahuan sebanyak-banyaknya tentang penerapan ISAK 35: Penyajian Laporan Keuangan Entitas Berorientasi Nonlaba melaui sesi tanya jawab.

\section{HASIL DAN PEMBAHASAN}

Kegiatan sosialisasi kepada pengurus Masjid Al-Aulia dilaksanakan selama tiga hari yang berlangsung dari tanggal 13 hingga 15 November 2020. Adapun susunan acara pelatihan sebagai berikut:

Tabel 1. Susuna Acara

\begin{tabular}{|c|l|l|c|}
\hline No & Hari Tanggal & \multicolumn{1}{|c|}{ Materi } & Waktu \\
\hline 1 & Jumat, & \begin{tabular}{l} 
Pembukaan dan perkenalan \\
\cline { 3 - 4 }
\end{tabular} & $\begin{array}{l}\text { Pengantar /Pendahuluan } \\
\text { Mengenai Organisasi Nirlaba }\end{array}$ \\
\hline
\end{tabular}




\begin{tabular}{|c|l|l|l|}
\hline No & Hari Tanggal & \multicolumn{1}{|c|}{ Materi } & Waktu \\
\cline { 3 - 4 } & $\begin{array}{l}\text { Sabtu } \\
14 \text { November } \\
2020\end{array}$ & & $09.00-$ \\
& & Pengenalan Akuntansi Dasar & 14.00 \\
\hline 5 & $\begin{array}{l}\text { Minggu } \\
15 \text { November } \\
2020\end{array}$ & $\begin{array}{l}\text { Sosialiasi ISAK 35 untuk penyajian } \\
\text { laporan keuangan organisasi nirlaba }\end{array}$ & $09.00-$ \\
\cline { 3 - 4 } & & Tanya jawab dan diskusi & 11.30 \\
\hline
\end{tabular}

Berdasarkan tanya jawab dan pengamatan langsung selama kegiatan berlangsung, Pengabdian Kepada Masyarakat ini memberikan kontibusi bagi para peserta berupa:

1. Pemahaman akan laporan keuangan, proses penyusunan dan fungsi laporan keuangan khususnya untuk organisasi nirlaba.

2. Keuntungan tersedianya laporan keuangan bagi Masjid Al-Aulia untuk mendapatkan calon investor,

3. Pengetahuan penyusunan laporan keuangan,

4. Kontribusi yang dapat diberikan bagi lingkungan sekitar.

Dalam pelaksanaan PKM, para peserta diminta untuk aktif dalam kegiatan diskusi, mengajukan pertanyaan, aktif dalam mencoba untuk menyusun laporan keuangan. Peserta juga diminta untuk mencoba mencari solusi bagi kendala yang selama ini dihadapi menurut pemahaman masing - masing agar dapat menjadi diskusi dalam pelaksanaan PKM.

Beberapa faktor yang mendukung keberhasilan kegiatan ini adalah minat peserta untuk mampu menyusun laporan keuangan seara mandiri, selain dapat menjadi pengetahuan bagi peserta sekaligus dapat membantu pertanggungjawaban atas pelaksanaan renovasi masjid. Faktor yang dirasakan menghambat adalah keterbatasan waktu dalam pelaksanaan PKM karena pengurus Masjid juga harus tetap melaksanakan kewajibannya. Penyampaian materi disampaikan oleh narasumber Jaenal Abidin S.Pd., M.Akt tentang ISAK 35.

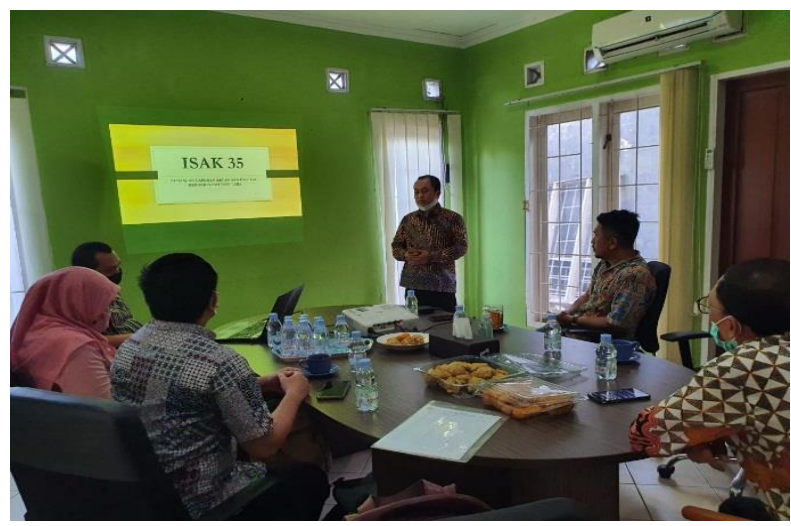

Gambar 1. Pemaparan materi 
Berikut ini dokumen diskusi oleh Bapak Hidayat Zulkarnaen selaku ketua pembangunan Masjid Al-Aulia

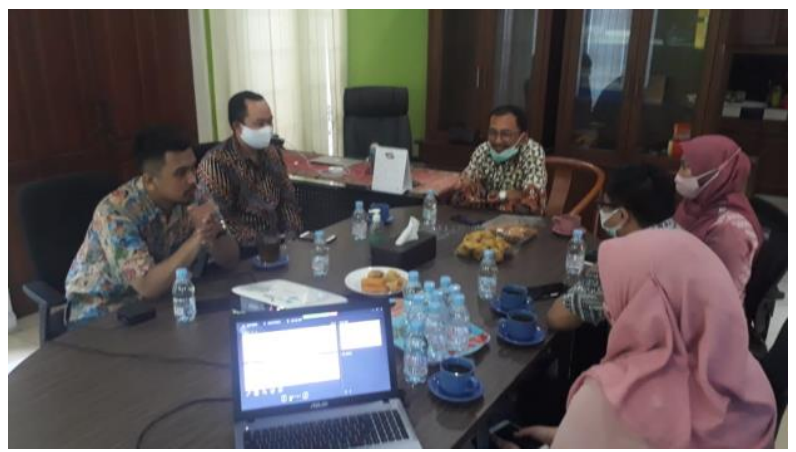

Gambar 2. Sesi diskusi dan tanya jawab

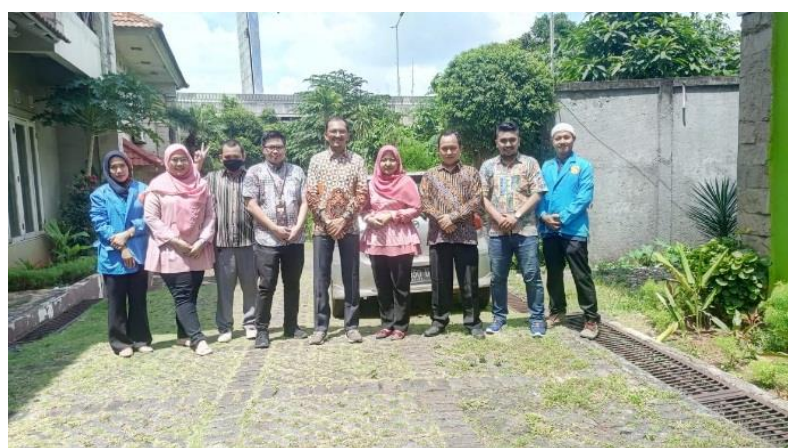

Gambar 3. foto bersama peserta PKM

\section{KESIMPULAN}

Berdasarkan hasil pengamatan dan interviu secara sampling terhadap peserta, dapat disimpulkan bahwa pelaksanaan PKM memberikan wawasan baru bagi peserta tentang penyusunan laporan keuangan dan pemahaman akan pentingnya laporan yang tepat dan akuntabel dalam mencari calon donatur.

Dengan mengikuti PKM, selain mendengarkan pemaparan dalam penyusunan laporan keuangan, para peserta juga melakukan diskusi mengenai kendala yang dihadapai dalam pengelolaan dana dan pelaporannya yang tepat dan mudah dipahami oleh pengguna laporan keuangan.

\section{DAFTAR PUSTAKA}

Hery. (2009). Teori Akuntansi. Edisi 1. Cetakan ke 2. Jakarta: Kencana.

IAI. (2009). Standar Akuntansi Keuangan per 1 Juli 2009. Jakarta : Salemba Empat

Kasmir. (2015). Analisis Laporan Keuangan. Cetakan ke 8. Jakarta: PT RajaGrafindo Persada 
Vol 3, No. 2, 2020

Stice, James D., Earl K. Stice, dan K. Fred Skousen. (2009). Akuntansi Keuangan atau Intermediate Accounting. Buku 1. Edisi 16. Penerjemah: Ali Akbar. Jakarta: Penerbit Salemba Empat.

Exposure Draft ISAK 35: Penyajian Laporan Keuangan Entitas Berorientasi. (2018). IAI: Jakarta Selatan. 